\title{
Shock-elicited aggression is influenced by lead and/or alcohol exposure
}

\author{
STEPHEN F. DAVIS, SARA L. W. ARMSTRONG, and MATTHEW T. HUSS \\ Emporia State University, Emporia, Kansas
}

\begin{abstract}
Lead-exposed, alcohol-exposed, lead-and-alcohol exposed, and control rats received shock-elicited aggression testing. Lead-exposed and alcohol-exposed animals made significantly more aggressive responses than did the other two groups. These results support previous data by showing that lead exposure may result in increased emotionality and may counteract the effects of alcohol.
\end{abstract}

Recent reports have shown that lead contamination results in an increase in emotionality in humans (Baker, Feldman, White, \& Harley, 1983; David, Clark, \& Voeller, 1972) and animals (Flynn, Flynn, \& Patton, 1979). For example, chronic lead exposure has been shown to exacerbate reactivity to primary (Nation, Baker, Fantasia, Ruscher, \& Clark, 1987) and secondary (Nation, Clark, Bourgeois, \& Rogers, 1982) aversive stimuli. Likewise, a recent study by Davis, Nation, and Mayleben (1993) demonstrated that lead-exposed animals experiencing partial reinforcement runway training prior to extinction took longer to extinguish the running response than did unexposed partial-reinforcement animals. These results were interpreted as reflecting stronger conditioning of frustration-generated cues to the instrumental running response by the lead-exposed animals during partialreinforcement training. Thus, when extinction was begun, the lead-exposed animals persisted longer than those not exposed to lead.

Similarly, Davis, Freeman, and Nation (1993) reported two experiments in which stronger taste aversions were developed by lead-exposed rats. These results were attributed to the increased reactivity of the lead-exposed animals, which facilitated the formation of additional/ stronger taste-illness associations.

The increase in reactivity, especially to aversive stimuli, displayed by lead-exposed animals suggests that subjects treated in this manner will display higher levels of aggressiveness than untreated subjects. One purpose of the present research was to test this prediction.

Previous reports indicating that alcohol exposure may (1) increase responding in the shock-elicited aggression situation (Tramill, Wesley, \& Davis, 1981) and (2) counteract the effects of lead exposure (e.g., Nation, Grover, \& Bratton, 1991) provided a second impetus for this research. Specifically, it was predicted that those exposed only to alcohol would display higher levels of aggression than those exposed to both lead and alcohol. Whether or not the aggression of animals exposed to both lead and

Requests for reprints may be addressed to S. F. Davis, Department of Psychology, Emporia State University, Emporia, KS 66801. alcohol would fall below or remain above that of a group of control animals was subject to experimental determination, as was the relative performance of the groups exposed only to alcohol or lead.

\section{METHOD}

\begin{abstract}
Subjects
Twenty-seven naive, male Holtzman rats served as subjects. The subjects were 39 days old at the beginning of the experiment and 113 days old at the time of aggression testing. All the animals were individually caged with food and fluids available on a free-feeding basis for the duration of the experiment.
\end{abstract}

\section{Apparatus}

Testing took place in a shock-elicited aggression apparatus consisting of an opaque restraint tube $(21.5 \mathrm{~cm}$ in length, $7.5 \mathrm{~cm}$ in diameter) with one open and one closed end, a shock source (Campden Instruments Ltd., Model 521C), a target rod (Lafayette Instruments, Model 80111, omnidirectional lever), an impulse counter (Lafayette Instruments, Model 5822), and a digital electronic timer (Lafayette Instruments, Model 54030). An attack upon the target rod, which extended across the midportion of the open end of the restraint tube, activated the impulse counter and the timer, thus yielding an automated record of the number of responses and duration of aggression (in seconds) for each subject.

The subject's tail was extended through a $1.50-\mathrm{cm}$ hole in the closed end of the restraint tube. When a subject was in place in the restraint tube, a wooden dowel rod was secured to the tail by means of adhesive tape, thus prohibiting escape during shock testing. Two copper wires, $7 \mathrm{~cm}$ apart and permanently attached to the dowel rod, served as electrodes for the administration of tailshock.

\section{Procedure}

Seventy-three days prior to aggression testing, four groups of subjects were randomly formed: Group $\mathrm{Pb}$ (lead exposed, $n=7$ ), Group Pb-ETOH (lead and alcohol exposed, $n=7$ ), Group ETOH (alcohol exposed, $n=7$ ), and Group WAT (water-exposed controls, $n=6$ ). For the ensuing 74 days (including the day of aggression testing), the subjects in Groups $\mathrm{Pb}$ and $\mathrm{Pb}$-ETOH received lead exposure. Lead exposure was accomplished by mixing $.92 \mathrm{~g}$ of lead acetate per $1 \mathrm{~L}$ of water; this procedure yielded a solution consisting of $500 \mathrm{ppm}$ lead. This solution was available on an ad-lib basis. The remaining animals were maintained on plain tap water.

On each of the 14 days that immediately preceded aggression testing (59 days after the inception of lead exposure), the subjects in Groups ETOH and Pb-ETOH were injected interperitoneally with $.25 \mathrm{cc} / 100 \mathrm{~g}$ body weight of $.30 \%$ ethanol $(\mathrm{v} / \mathrm{v})$ in isotonic saline. The subjects in Groups $\mathrm{Pb}$ and WAT received a comparable injection of isotonic saline on each of these days. These injections were also administered on the day of aggression testing. Thus, including aggression testing, 
Group $\mathrm{Pb}$ received 74 days of lead exposure including 15 days of saline injections, and Group Pb-ETOH received 74 days of lead exposure including 15 days of alcohol injections. The subjects in Group ETOH received 15 days of alcohol injections, and Group WAT received 15 days of saline injections.

On the day of aggression testing, each subject was individually tested $15 \mathrm{~min}$ after receiving its designated injection. Following a 5-min habituation period in the apparatus, each subject received a 10-min period of tailshock administration. During this time, $1.50-\mathrm{mA}$ shocks $300 \mathrm{msec}$ in duration were administered at 3-sec intervals. Thus, each subject received a total of 200 shocks. The order for running the subjects was randomized. The number of aggressive responses and the duration of aggressive responding (in seconds) were recorded for each animal.

\section{Results}

Prior to analysis, the response data were converted to $\log _{10}\left(X_{i}+1\right)$ scores. Group mean responses are shown in Figure 1. Analysis of variance of the response data yielded significance for the groups factor $[F(3,23)=$ $6.089, p=.003]$. Subsequent Newman-Keuls tests indicated that although Groups $\mathrm{Pb}$ and ETOH did not differ significantly from each other, they made significantly $(p<.01)$ more aggressive responses than did Groups WAT and Pb-ETOH, which did not differ reliably from each other.

Group mean duration of aggression scores (in seconds) are shown in Figure 2. Analysis of these data yielded a significant groups effect $[F(3,23)=7.149, p=.001]$. Subsequent Newman-Keuls tests indicated that Group $\mathrm{Pb}$ made significantly $(p<.01)$ longer contact with the target rod than all the other groups. In turn, Group ETOH had significantly $(p<.01)$ longer duration scores than did Groups Pb-ETOH and WAT, which did not differ reliably.

\section{DISCUSSION}

The elevated levels of aggressive responding shown by Group ETOH, compared with Group WAT, replicates previous data reported by Tramill

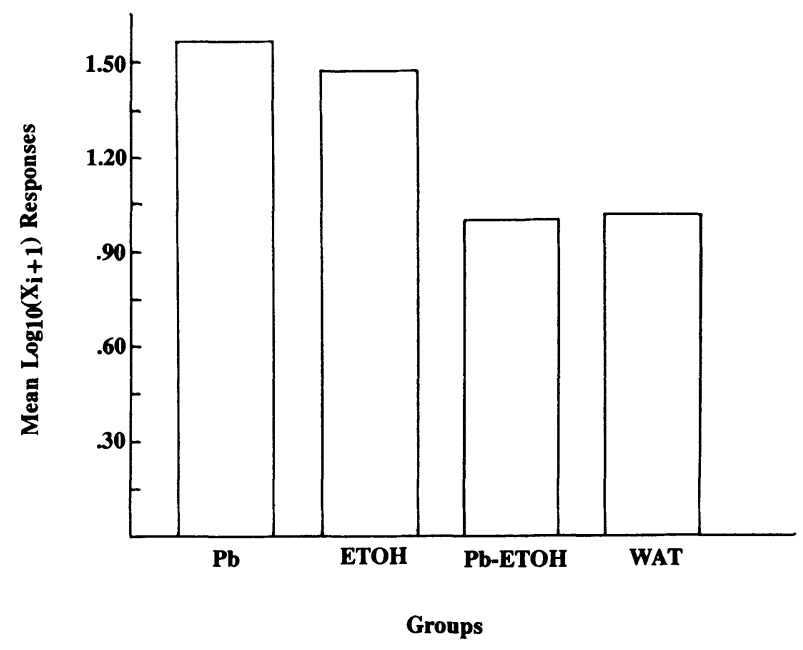

Figure 1. Mean $\log _{10}\left(X_{i}+1\right)$ aggressive responses for Groups $\mathrm{Pb}$ (lead exposed), ETOH (alcohol exposed), Pb-ETOH (lead and alcohol exposed), and WAT (water-exposed controls).

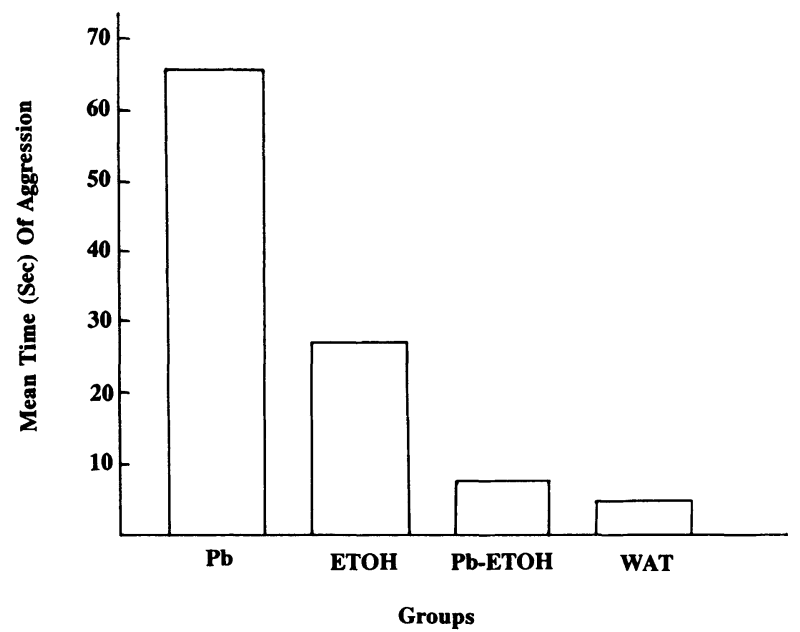

Figure 2. Group mean duration of aggression (in seconds) for Groups Pb (lead exposed), ETOH (alcohol exposed), Pb-ETOH (lead and alcohol exposed), and WAT (water-exposed controls).

et al. (1981). Thus, one conclusion prompted by the present data is that chronic administration of alcohol results in heightened levels of aggression.

The lack of significant differences in the number of responses between the lead-exposed (Group $\mathrm{Pb}$ ) and alcohol-exposed (Group ETOH) subjects indicates that, compared with the control condition (Group WAT), these treatments increased the display of aggressive responding in a similar manner. However, Group $\mathrm{Pb}$ displayed significantly longer durations, so it is equally apparent that lead exposure resulted in longer timeper-attack scores than did alcohol exposure. One explanation for this result concerns the nocioceptive effects of the aversive stimulus on the lead-treated animals. It has been suggested (Nation et al., 1987) that lead exposure engenders greater discomfort to aversive stimuli. In the present situation, this greater discomfort was translated into longer timeper-attack scores. Had the lead-treated animals (Group $\mathrm{Pb}$ ) not displayed longer duration scores, it is arguable that they would have shown significantly more responses than the alcohol-exposed subjects (Group ETOH).

The finding that the aggressive response and duration scores of the lead-and-alcohol exposed animals (Group Pb-ETOH) fell significantly below those of the lead-exposed (Group $\mathrm{Pb}$ ) and alcohol-exposed (Group ETOH) animals indicates that lead exposure serves to counteract the increased aggression engendered by alcohol exposure alone. These data agree with the Nation et al.'s (1991) report that demonstrated a reduction in punished licking behavior as a function of simultaneous alcohol and lead treatment. Clearly, additional research is required to ascertain the extent to which this antagonistic alcohol-lead relationship can be generalized to other situations and behaviors.

\section{REFERENCES}

Baker, E. L., Feldman, R. G., White, R. E., \& Harley, J. P. (1983). The role of occupational lead exposure in the genesis of psychiatric and behavioral disturbances. Acta Psychologica Scandinavia, 67(Suppl. 303), 38-48.

David, O. J., Clark, J., \& Voeller, K. (1972). Lead and hyperactivity. Lancet, 2, 900-903.

Davis, S. F., Freeman, B. L., \& Nation, J. R. (1993). The effects of chronic lead exposure on taste-aversion conditioning in rats. The Psychological Record, 43, 205-214.

Davis, S. F., Nation, J. R., \& Mayleben, M. A. (1993). The effects of chronic lead exposure on reactivity to frustrative nonreward in rats. Toxicology Letters, 66, 237-246.

FlynN, J. C., FlynN, E. R., \& Patton, J. H. (1979). Effects of prenatal and post-natal lead on affective behavior and learning in the rat. Neurobehavioral Toxicology, 1(Suppl. 1), 93-103. 
Nation, J. R., Baker, D. M., Fantasia, M. A., Ruscher, A. E., \& ClARK, D. E. (1987). Ethanol consumption and free-operant avoidance performance following exposure to dietary lead. Neurotoxicology, 8, 561-569.

Nation, J. R., Clark, D. E., Bourgeois, A. E., \& Rogers, J. K (1982). Conditioned suppression in the adult rat following chronic exposure to lead. Toxicology Letters, 14, 63-67.

Nation, J. R., Grover, C. A., \& Bratton, G. R. (1991). Behavioral antagonism between lead and cadmium. Neurotoxicology \& Teratology, 12, 99-104.

Tramill, J. L., Wesley, A. L., Davis, S. F. (1981). The effects of chronic ethanol challenges on aggressive responding in rats maintained on a semideprivation diet. Bulletin of the Psychonomic Society, 17, 51-52.

(Manuscript received May 14, 1993.) 